\title{
THE NATURAL HISTORY AND MANAGEMENT OF RECURRENT CORNEAL EROSION: A PROSPECTIVE RANDOMISED TRIAL
}

\author{
P. G. HYKIN, A. E. FOSS, C. PAVESIO and J. K. G. DART \\ London
}

\begin{abstract}
SUMMARY
One hundred and seventeen patients with a history of recurrent corneal erosion were recruited at initial hospital presentation. Seventy-five cases had a history of shallow corneal injury, 23 had epithelial basement membrane dystrophy (EBMD), 8 had both and 11 had neither. Mean age at presentation was 38 years and follow-up ranged from 6 to 16 months (mean 10.6 months). Sixty-one patients presented with a first acute corneal erosion, 21 with a subsequent acute corneal erosion and 35 with chronic symptoms. Patients with EBMD or a traumarelated focal epithelial basement membrane abnormality were more likely to present with chronic recurrent symptoms than trauma-related cases with no abnormality on examination. Both EBMD and trauma-related cases typically recurred in the lower half of the cornea, frequently in the midline $(z=7.3, p<0.0001)$, suggesting an intrinsic or acquired abnormality of the epithelial basement membrane at this site. Only four of 82 acute episodes did not resolve by 5 days with simple patching, cycloplegia and topical antibiotic ointment. In the vast majority of patients presenting with an acute erosion, simple management measures only are required. Of 117 cases started on prophylactic ointment at night, further therapy due to prophylaxis failure was required in only 5 . EBMD was a risk factor for failure (relative risk 10.77). There was no difference in efficacy between once daily prophylactic paraffin and hypertonic saline ointments $(p=0.17)$, suggesting they both have only a lubricant action.
\end{abstract}

Recurrent corneal erosion (RCE) is a common disorder of the epithelial basement membrane. It is frequently associated with a previous history of shallow corneal injury ${ }^{1.2}$ or epithelial basement membrane dystrophy (EBMD). ${ }^{3.4}$ Abnormal epithelial basement membrane or abnormal deposition of normal epithelial basement membrane are believed to be central to the pathogenesis. Clinically RCE

From: Moorfields Eye Hospital, London, UK.

Correspondence to: Philip G. Hykin, FRCS, Moorfields Eye Hospital, City Road, London EC1V 2PD, UK. is characterised by recurrent episodes of early-morning pain. photophobia and lacrimation. ${ }^{3.5 \cdot 7}$ In the majority of cases, the acute episode is successfully managed by patching, cycloplegia and topical antibiotic ointment, with prophylactic ointment at night to prevent further episodes. ${ }^{4,6}$ In a minority of cases, these measures are insufficient and recurrent painful episodes occur. The natural history and precipitating factors of these episodes are ill understood. Alternative treatment modalities, including therapeutic contact lens wear, ${ }^{7.8}$ anterior stromal puncture, ${ }^{9.10}$ total superficial keratectomy ${ }^{11.12}$ and $\mathrm{Nd}: \mathrm{YAG}^{13.14}$ and excimer laser therapy have been undertaken but their relative efficacy has been difficult to assess because of the varied indications applied to their use. This study therefore attempts to define, by following a cohort of patients for a prolonged period of time, the clinical characteristics predictive of a poor prognosis and the natural history of the disorder, and compares alternative treatment and prophylactic methods in different clinical situations according to a predefined treatment algorithm (Fig. 1).

\section{METHODS}

Patients were enrolled between January 1991 and March 1992 at initial hospital presentation with either an acute first episode of RCE, a further acute episode or chronic symptoms. A first episode of RCE was defined as either: (1) characteristic symptoms of early-morning pain, photophobia and lacrimation, a history of trauma to the affected eye and an acute corneal erosion, or (2) characteristic symptoms, an acute corneal erosion and signs of EBMD. Subsequent episodes were diagnosed on the basis of characteristic symptoms, signs of an acute corneal erosion and a history of a previous acute episode. Chronic cases were diagnosed on the basis of a prolonged typical history of RCE with or without a history of trauma or signs of EBMD, and this group included 6 patients who at no time had a recorded RCE.

At initial presentation a detailed history and examination by slit lamp microscopy was performed. EBMD was 


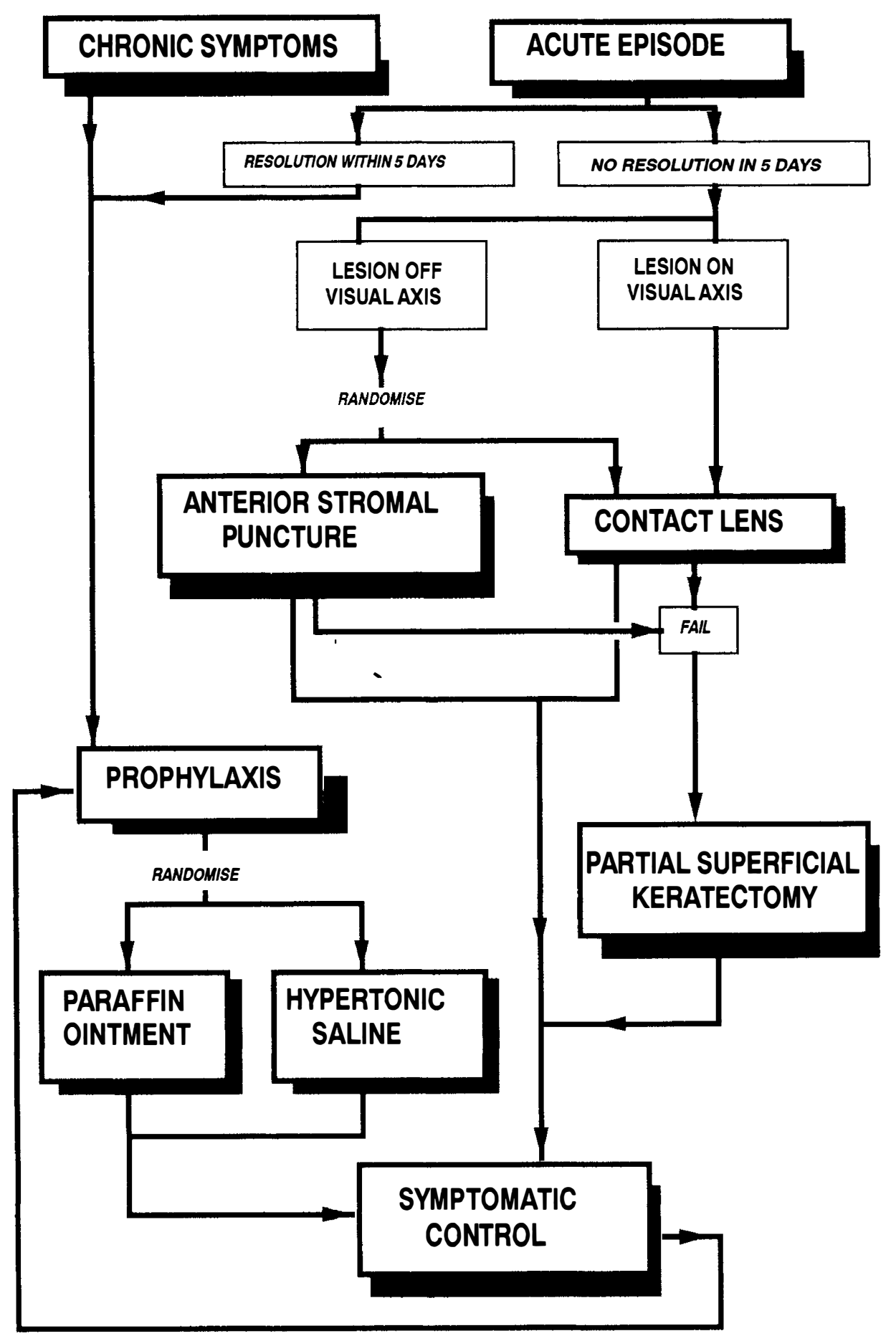

Fig. 1. Management algorithm.

diagnosed using a broad tangential beam or retroillumination from a dilated pupil. A history of trauma, the presence of EBMD and the presence of a focal epithelial basement membrane abnormality, were employed to classify patients into one of six categories (Table I).

A focal epithelial basement membrane abnormality of the cornea was defined as a unilateral localised area of abnormality, usually intra-epithelial microcystic change. EBMD was defined as the presence of microcystic, fingerprint or map change in the epithelia of both eyes, in the contralateral eye to the presenting acute episode, or in either eye with a positive family history. At presentation with an acute corneal erosion the site and the size of the lesion were recorded by involved sectors on a corneal chart (Fig. 2). Involvement of 0-3 sectors was classified as small, 4-6 sectors as moderate, 7-9 as large and 10-12 as very large. The distributions of EBMD lesions were recorded in both eyes at presentation on the corneal chart.

Patients were excluded if the RCE was secondary to (1) Reis-Buckler's dystrophy and lattice and granular stromal dystrophy, (2) chemical or thermal corneal injury, (3) Salzmann's nodular degeneration and band kera- 


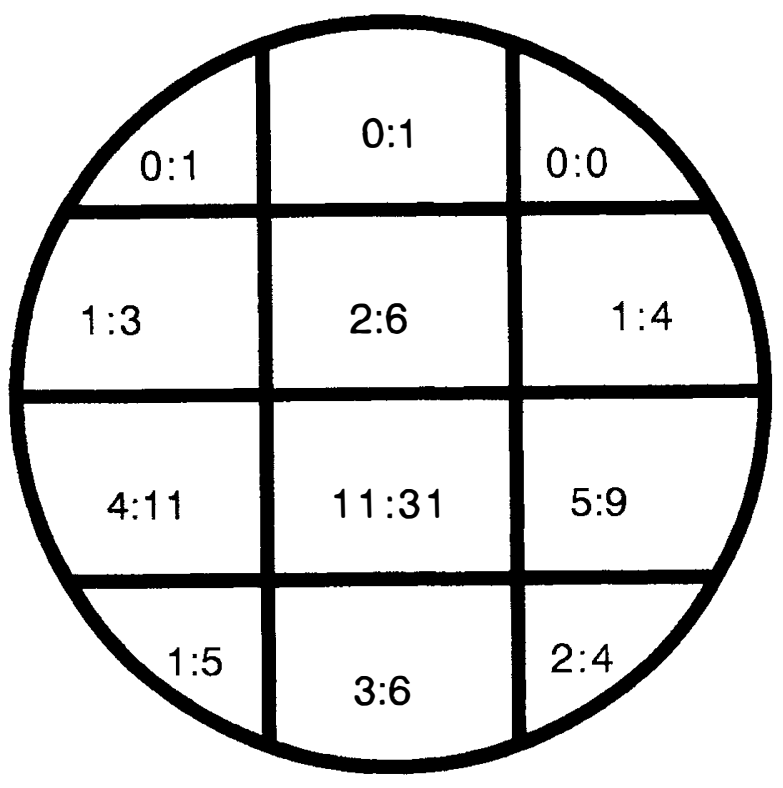

Fig. 2. Distribution of acute corneal erosions across the corneal surface. The numbers are the ratios of epithelial basement membrane dystrophy to trauma-related lesions. Involvement of the lower half of the cornea was more frequent in both groups $(z=7.3, p<0.0001)$.

topathy, (4) bullous keratopathy, (5) keratoconjunctivitis sicca, (6) neurotrophic keratitis or (7) neuroparalytic keratitis.

\section{Management of Acute Episodes}

The acute episode was managed with topical chloramphenicol ointment, cycloplegia and patching with review at 24 hours and 5 days. At 5 days, if the acute erosion had resolved, the patient was entered into the prophylactic arm of the managment algorithm (Fig. 1) and randomised into

Table I. Clinical categories of recurrent corneal erosion, patient numbers and type of presentation

\begin{tabular}{|c|c|c|c|c|}
\hline & \multirow[b]{2}{*}{$\begin{array}{c}\text { No. of } \\
\text { patients }\end{array}$} & \multirow[b]{2}{*}{$\%$} & \multicolumn{2}{|c|}{ Presentation } \\
\hline & & & $\begin{array}{l}\text { Acute } \\
\text { episode }\end{array}$ & $\begin{array}{l}\text { Chronic } \\
\text { symptoms }\end{array}$ \\
\hline $\begin{array}{l}\text { Category 1: A focal epithelial } \\
\text { basement membrane } \\
\text { abnormality and a history of } \\
\text { trauma }\end{array}$ & 42 & 36 & 27 & 15 \\
\hline $\begin{array}{l}\text { Category 2: A focal epithelial } \\
\text { basement membrane } \\
\text { abnormality, no history of } \\
\text { trauma }\end{array}$ & 5 & 4 & 5 & 0 \\
\hline $\begin{array}{l}\text { Category } 3 \text { : Epithelial basement } \\
\text { membrane dystrophy and a } \\
\text { history of trauma }\end{array}$ & 8 & 7 & 5 & 3 \\
\hline $\begin{array}{l}\text { Category 4: Epithelial basement } \\
\text { membrane dystrophy, no history } \\
\text { of trauma }\end{array}$ & 23 & 20 & 13 & 10 \\
\hline $\begin{array}{l}\text { Category } 5: \text { A history of trauma } \\
\text { to the affected eye, but no } \\
\text { corneal abnormality }\end{array}$ & 33 & 28 & 28 & 5 \\
\hline $\begin{array}{l}\text { Category 6: Characteristic } \\
\text { symptoms of recurrent corneal } \\
\text { erosion and normal cornea }\end{array}$ & 6 & 5 & 4 & 2 \\
\hline Totals & 117 & 100 & 82 & 35 \\
\hline
\end{tabular}

receiving prophylactic topical paraffin or hypertonic saline ointment nocte. If the acute episode had failed to resolve or prophylactic measures had failed, the patient entered the treatment arm of the algorithm. If the lesion involved the visual axis, the patient was managed with a therapeutic contact lens, but if not the patient was randomised into treatment by anterior stromal puncture or a therapeutic contact lens. If either of these techniques failed to control symptoms a partial superficial keratectomy (anterior to Bowman's membrane) was performed. Patients in whom this failed to control symptoms were withdrawn from the study and considered for total superficial keratectomy or excimer laser therapy. Patients presenting with chronic symptoms without an acute lesion were immediately randomised for prophylaxis.

\section{Treatment Modality Regimens}

Hydrogel (80\% water content) therapeutic soft contact lenses were used where indicated. After initial fitting, the lens was reviewed at 24 hours and, if the fit was satisfactory and the eye quiet, it was left in situ for 6 weeks. If the patient was asymptomatic for 6 weeks, the lens was removed and the patient randomised for prophylaxis. If symptoms persisted at 6 weeks, lens wear was continued until no symptoms had occurred for 6 weeks. The patient was instructed to report to the hospital immediately the eye became red or painful. Once the eye was asymptomatic the lens was removed and the patient entered into the prophylaxis arm of the management algorithm.

Anterior stromal puncture was performed using a purpose-designed needle (Look Inc.) with a $0.1-0.3 \mathrm{~mm}$ turned end, to protect against the risk of inadvertent corneal perforation. Puncture marks were made $1 \mathrm{~mm}$ apart to the level of Bowman's membrane over the area of affected corneal epithelium and extending for $1 \mathrm{~mm}$ onto normal surrounding cornea.

Partial superficial keratectomy was defined as removal of the corneal epithelium to within $2 \mathrm{~mm}$ of the limbus with subsequent removal of basement membrane with centripetal strokes using a no. 14 Bard Parker blade. Total superficial keratectomy was defined as the above with additional removal of epithelium to the limbus.

\section{Prophylaxis}

Prophylactic ointment consisted of either hypertonic saline or paraffin ointment applied once daily at night, by pulling down the lower lid and applying ointment the length of the inferior conjunctival fornix. After randomisation with prophylactic agents, all patients were reviewed at 3 months, and categorised as: (1) asymptomatic, (2) controlled, defined as 'some symptoms experienced, but insufficient to interfere with the patient's daily routine', or (3) failures, defined as 'patients in whom a recurrent acute erosion had occurred or chronic symptoms troublesome enough to interfere with the patient's daily activities'. Prophylaxis was stopped in group 1, continued in group 2, with 3 monthly review, and group 3 patients were entered into the treatment arm of the algorithm and 
Table II. Results of prophylactic treatment with hypertonic saline and paraffin ointments

\begin{tabular}{|c|c|c|c|c|c|c|}
\hline \multirow[b]{2}{*}{ Prophylaxis: } & \multicolumn{2}{|c|}{ Asymptomatic } & \multicolumn{2}{|c|}{ Symptomatic control } & \multicolumn{2}{|c|}{ Failure } \\
\hline & Paraffin & $\begin{array}{l}\text { Hypertonic } \\
\text { saline }\end{array}$ & Paraffin & $\begin{array}{l}\text { Hypertonic } \\
\text { saline }\end{array}$ & Paraffin & $\begin{array}{l}\text { Hypertonic } \\
\text { saline }\end{array}$ \\
\hline Trauma & 17 & 18 & 22 & 17 & 0 & 1 \\
\hline EBMD & 5 & 4 & 5 & 5 & 2 & 2 \\
\hline
\end{tabular}

managed as for non-resolving acute episodes. Patients who underwent anterior stromal puncture or superficial keratectomy recommenced prophylactic treatment at 10 days and were followed in the usual way. At 1 year, the 3 monthly review was discontinued and yearly review instituted, with additional visits at the patient's request.

\section{Statistical Methods}

The difference in the incidence of lesions in the superior and inferior cornea was compared using Student's $t$ test ( $z$ score). As selected cell values were less than 5, Fisher's exact test was used to compare the efficacy of prophylactic hypertonic saline and paraffin ointment, and the relative risk of prophylactic treatment failure for the EBMD and trauma-related groups was estimated from-Fisher's exact test.

\section{RESULTS}

\section{Clinical Characteristics of the Study Group}

One hundred and seventeen patients were recruited to the study with follow-up ranging from 6 to 16 months (mean 10.6 months). The average age of the patients was 38 years (range 14-80 years); 55 were male and 62 female. The numbers of patients recruited to each group (Table I) showed that category 1, a focal EBM abnormality and a history of trauma, comprised the largest group (36\%). Method of presentation (Table I) was by acute corneal erosion in $70 \%$ and by chronic recurrent symptoms in $30 \%$. Of patients presenting with an acute corneal erosion, $70 \%$ had pain or lacrimation on waking, $20 \%$ were awoken by pain during the night, and $10 \%$ had an atypical presentation such as pain during the day. There was no correlation of these presentations with patient category. Chronic symptoms ranged from mild episodes of pain occurring once a month to pain each morning, and were a more common method of presentation in EBMD cases of category 4 $(43 \%)$ than in trauma-related cases of categories 1 and 5 $(26 \%)$. The history of trauma given by patients in groups 1,3 and 5 ranged from 2 weeks to 45 years beforehand (median 3 months), the commonest means being a child's fingernail or a clothes brush. There was no correlation of patient category with type or timing of injury. The site of original trauma was frequently unknown.

Of patients presenting with an acute first episode of RCE, $36 \%$ with EBMD and $46 \%$ with a history of trauma had a lesion partially or totally involving the midline below the horizontal meridian (Fig. 2). In both groups there was a clear predilection for the lesion to involve the lower half of the cornea compared with the upper $(z=7.3$, $p<0.0001)$. There was no difference in the overall size of the acute erosion when first seen; 11 of $13(88 \%)$ cases with EBMD had a small lesion and 54 of $55(98 \%)$ with a history of trauma. In the former group it was frequently in or adjacent to an area of fingerprint or microcystic change, but the extent of the latter did not correlate with the size of the acute erosion. In only 2 cases was an anterior uveitis present in conjunction with the acute lesion. There was no correlation between symptom pattern in terms of time of onset and size and position of the corneal lesion.

\section{Natural History}

Of patients presenting with an acute episode, only 4 of 82 had failure of this episode to resolve at 5 days. All 4 patients had presented with an acute first episode. One case developed an anterior stromal infiltrate which, although sterile on bacterial culture, resolved on topical antibiotic therapy. The 3 remaining cases ( 2 in category 1 and 1 in category 4 ) had lesions involving the visual axis and were managed with a therapeutic contact lens. In all 3 cases the contact lens controlled symptoms; it was removed at 6 weeks and prophylaxis begun.

\section{Prophylaxis}

Of the patients randomised into prophylactic treatment with simple eye ointment, 39 had a history of trauma and 12 had EBMD; of those receiving hypertonic saline, 36 had a history of trauma and 11 had EBMD (Table I). There was no difference in the efficacy of the two ointments as prophylactic agents in their ability either to control symptoms or to abolish them completely (Fisher's test). Patients with EBMD had an increased risk of prophylactic failure (relative risk 10.77) and required further management.

Five patients were withdrawn from prophylactic treatment because of unacceptable symptoms. Four were treated with a contact lens. In 2 instances (one patient, both eyes) this failed to control symptoms and partial superficial keratectomy was performed in both eyes, which relieved but did not totally abolish symptoms. Anterior stromal puncture was performed in the fifth patient over a small area of inferior cornea, resulting in symptomatic control. These patients all then recommenced prophylactic treatment.

\section{DISCUSSION}

The largest category (36\%) of patients comprised those with a history of trauma to the cornea and a persistent focal epithelial basement membrane abnormality characterised 
by a localised area of microcyts. ${ }^{15}$ It has been assumed that this results in impaired attachment of the epithelial layer to underlying basement membrane. ${ }^{5}$ A recent study suggesting that most epithelial cells retain cytoplasmic extensions in contact with the basement membrane may make this more important than previously realised. ${ }^{16}$ The next largest patient group (category 5) comprised patients with a history of trauma but a clinically normal corneal epithelium. It is perhaps surprising that patients $(n=6)$ with a normal corneal epithelium should develop RCE, although it is possible that a subclinical abnormality of the epithelial basement membrane exists. It is interesting to note that one such patient subsequently developed symptoms consistent with RCE in his second eye, suggesting that an abnormality of the epithelial basement membrane existed in this eye also, although it was normal on examination. Patients with EBMD alone (23\%) and those with EBMD and a history of trauma (7\%) comprised a smaller percentage of cases than has previously been reported. ${ }^{1}$ In addition, 5 patients with an epithelial basement membrane abnormality in one eye but no history of trauma were recruited, suggesting trauma had passed unnoticed or that these cases represented a localised or subclinical form of EBMD. Six cases were identified in which no corneal abnormality was found despite a characteristic history, and it is assumed these cases may have had subclinical EBMD.

Analysis of symptom patterns in isolation and in the context of the six categories showed a trend for patients with EBMD and those with trauma and a focal epithelial basement membrane abnormality to have more recurrent symptoms than trauma-related cases. Although it has been stated that EBMD cases tend to develop microerosions while trauma-related cases ${ }^{6}$ develop large acute erosions, we found no difference in the size or site of acute erosions between these groups. No symptom pattern was found to be predictive of the effects of acute treatment or of prophylaxis failure. The majority of acute corneal erosions occurred wholly within the lower half of the cornea, irrespective of patient category. This was true in patients who initially experienced an episode of trauma and is at odds with a previous study. ${ }^{8}$ However, in a number of cases the site of the original injury was not known because the patient had either not sought medical attention at the time of the original injury or was seen elsewhere. It has been suggested that recurrences occur in close proximity to the Hudson-Stahli line and that this is a factor in recurrence. ${ }^{8}$ It may also be that in moderate- and large-sized erosions involving the central cornea, the last area to re-epithelialise is the area in the midline below the horizontal meridian because centripetally moving convex fronts of epithelium meet at this apex and alignment of different fronts of basement membrane takes longest at this point, ${ }^{17}$ predisposing it to subsequent breakdown. Other factors such as upper lid movement across the ocular surface and local tear film drying are also most likely to disrupt the surface at this site.

Over $95 \%$ of patients presenting with an acute corneal erosion were successfully managed with patching, cycloplegia and topical antibiotic ointment. This is in agreement with previous studies ${ }^{4.6}$ and suggests this treatment should be tried in all cases in the first instance. Debridement of corneal epithelium was not performed in this study because although it may reduce the time for acute erosions to heal ${ }^{4.6}$ it is not thought to influence the incidence of recurrences. If the acute corneal erosion had not resolved at 5 days, further management was initiated. This 5 day limit to conventional management was arbitrary, but was an attempt to limit prolonged patient morbidity extending continuously from the acute episode. ${ }^{11}$ Of 4 cases that required further management, 1 developed an anterior stromal infiltrate, which was treated as presumed microbial keratitis with hourly topical antibiotic therapy. This is an uncommon complication of recurrent corneal erosion. ${ }^{18}$ The other 3 were fitted with a therapeutic contact lens for 6 weeks which controlled symptoms and enabled subsequent prophylactic treatment to commence.

Of 5 patients in total fitted with a therapeutic contact lens, 1 required further management because symptoms were not controlled but no contact lens complications occurred. In accordance with previous reports, we believe therapeutic contact lens wear should only be used in RCE under close supervision and in recalcitrant cases to allow symptomatic relief and regeneration of epithelial basement membrane. A period of 6 weeks was considered the minimum period for lens wear on the basis of the time taken for epithelial basement membrane remodelling to occur in animals. ${ }^{19}$

Anterior stromal puncture was performed in 1 case without complication and almost totally abolished symptoms. Lesions involving the visual axis were not treated by anterior stromal puncture, which limited its use. Other authors have reported favourable results with this technique and have suggested that treatment across the visual axis is possible. ${ }^{9.10}$ We believe that although scars across the visual axis fade with time they may remain a source of troublesome glare to the patient.

All cases were randomised into prophylactic treatment with either hypertonic saline or paraffin ointment at night. There was no difference in the efficacy of these two ointments either in controlling symptoms attributable to RCE or in abolishing them completely. Simple eye ointment contained liquid paraffin 30\% and yellow soft paraffin $70 \%$. Hypertonic saline contained sodium chloride $5 \%$, freshly distilled water $14.5 \%$, lanolin $38 \%$, liquid paraffin $9.8 \%$ and yellow soft paraffin $32.7 \%$. The high proportion of lanolin is hydrophilic to the sodium chloride in solution and acts to emulsify it. It is widely believed that hypertonic saline is preferable to paraffin ointment because the emulsified 5\% sodium chloride enters the tear film and exerts an osmotic action which serves to keep the superficial cornea dehydrated and prevents lifting of the corneal epithelium. ${ }^{4.19 .20 .21}$ Hypertonic saline ointment (5\% sodium chloride in petrolatum/lanolin) has been shown to reduce corneal oedema, as measured by central corneal thickness, by up to $20 \%$ at 3-4 hours after dosage in 
patients with corneal oedema. ${ }^{22}$ This suggests the hypertonic saline ointment can exert an osmotic action via the tear film in patients with an intact corneal epithelium ${ }^{23}$ and significant corneal oedema. Whether it exerts an osmotic action that stabilises the corneal epithelium in patients with recurrent corneal erosion without corneal oedema is unknown and this study suggests it may not. Certainly if the corneal epithelium is traumatised it imbibes salt solutions and the salt exerts no useful osmotic effect. ${ }^{24}$ It may cause irritation and itchiness and its use seems unjustified at present in the prophylaxis of recurrent corneal erosion.

Patients with EBMD were at greater risk of prophylactic ointment failing to control symptoms than other groups and this is perhaps not surprising in view of their tendency towards more chronic persistent symptoms.

The vast majority of cases of acute epithelial erosions will resolve on simple conservative management and no more invasive form of therapy should be considered until the acute lesion has had adequate opportunity to heal. Patients with EBMD or a focal abnormality are more likely to have more chronic recurrent symptoms than cases normal on examination. Prophylaxis with paraffin or hypertonic saline ointment is equally effective. EBMD cases are more likely to fail on prophylactic treatment than other cases. Few cases required further management, and were characteristically cases with EBMD or a focal epithelial basement membrane abnormality.

The authors would like to thank Mr. P. Wright and Mr. R. Buckley for allowing them to study patients under their care. This work was supported by Moorfields Eye Hospital Locally Organised Grant no. L/93/23.

Key words: Anterior basement membrane dystrophy, Anterior stromal puncture, Bandage contact lens, Epithelial basement membrane dystrophy, Map-dot-fingerprint dystrophy, Hypertonic saline solution, Therapeutic contact lens.

\section{REFERENCES}

1. Waring GO, Rodrigues MM, Laibson PR. Corneal dystrophies. 1. Dystrophies of the epithelium, Bowman's layer and stroma. Surv Ophthalmol 1978;23:71-122.

2. Messer G, Isakow I, Dabush S. Post-traumatic recurrent corneal erosion. Metabolic Paediatr Syst Ophthalmol 1983;7: 59-63.

3. Dohlman CN. Healing problems in the corneal epithelium. Jpn J Ophthalmol 1981;25:131-4.

4. Findley FM. Recurrent corneal erosions. J Am Optom Assoc 1986;57:392-6.
5. Wood TO, McLaughlin. Recurrent erosion. Int Ophthalmol Clin 1988;28:83-93.

6. Bron AJ, Brown N. Recurrent erosion of the cornea. Br J Ophthalmol 1976;60:84-91.

7. Mindel J. Therapeutic uses of contact lenses. Surv Ophthalmol 1989;33:381-94.

8. Williams R, Buckley R. Pathogenesis and treatment of recurrent corneal erosion. Br J Ophthalmol 1985;69:435-7.

9. MacLean EN, McRae SM, Rich LF. Recurrent erosion: treatment by anterior stromal puncture. Ophthalmology 1986:93:784-7.

10. MacRae SM, MacLean EN, Rich LF. Anterior stromal puncture for recurrent corneal erosion: further experience and new instrumentation. Ophthalmic Surg 1990;21:318-26.

11. Buxton JN, Constad WH. Superficial epithelial keratectomy. Cornea 1987;6:292-7.

12. Buxton JN, Constad WH. Superficial epithelial keratectomy in the treatment of epithelial basement membrane dystrophy. Ann Ophthalmol 1987;19:92-6.

13. Geggel HS. Successful treatment of recurrent corneal erosion with Nd:YAG anterior stromal puncture. Am J Ophthalmol 1990;110:404-7.

14. Rubinfeld RS, MacRae SM, Laibson PR. Successful treatment of recurrent corneal erosion with Nd:YAG anterior stromal puncture. Am J Ophthalmol 1991;111:252-3.

15. Waltmann S. Recurrent corneal erosion. Arch Ophthalmol 1989; 107:1436.

16. Lavker RM, Dong G, Cheng SZ, Kudah K, Corsarelis G, Sun T-T. Relative proliferative rates of limbal and corneal epithelia. Invest Ophthalmol Vis Sci 1991;32:1864-75.

17. Dua HS, Forrester JV. The corneoscleral limbus in human corneal epithelial wound healing. Am J Ophthalmol 1990; 10:646-56.

18. Shoch DE, Stock EL. Stromal keratitis complicating anterior membrane dystrophy. Am J Ophthalmol 1985;100: 199-201.

19. Grayson M. Diseases of the cornea. St Louis: Mosby, 1979: 136-7, 200-3.

20. Fraunfelder FT, Roy FH. Current ocular therapy. Philadelphia: Saunders, 1980:362-3.

21. Kenyon KR, Fogle JA, Grayson M. Dysgenesis, dystrophies and degenerations of the cornea. In: Duane TD, editor. Clinical ophthalmology, vol. 4. Hagerstown: Harper and Row, 1982:15,18-20.

22. Luxenberg MN, Green K. Reduction of corneal oedema with topical hyperosmotic agents. Am J Ophthalmol 1971; 71:847-53.

23. Lamberts DW. Topical hyperosmotic agents and secretory stimulants. Int Ophthalmol Clin 1980;20:163-9.

24. Jaanus S. Topical hyperosmotic agents. In: Bartlett JD, Jaanus SD, editors. Clinical ocular pharmacology. 2nd edition. London: Butterworths, 1989:277. 